\title{
Nanocrystalline Cellulose Based on Chitosan Hydrogel Structure as a Biological Adsorbent for Effluent of Fish Culture Farms
}

\section{Fatemeh Darabitabar}

Khorramshar Marine Science and Technology University: Khorramshahr Marine Science and Technology University

vahid yavari ( $\square$ yavarivahid@yahoo.com )

Khorramshar Marine Science and Technology University: Khorramshahr Marine Science and Technology University

\section{Aliakbar Hedayati}

Gorgan University of Agricultural Sciences and Natural Resources https://orcid.org/0000-0001-7658-5314

\section{Mohammad Zakeri}

Khorramshar Marine Science and Technology University: Khorramshahr Marine Science and Technology University

\section{Hossein Yousefi}

Gorgan University of Agricultural Sciences and Natural Resources

\section{Research Article}

Keywords: Nanocrystalline cellulose, Chitosan, Freshwater Deficiency, Wastewater, Agricultural Waste

Posted Date: March 1st, 2022

DOI: https://doi.org/10.21203/rs.3.rs-1348001/v1

License: (c) (i) This work is licensed under a Creative Commons Attribution 4.0 International License. Read Full License 


\section{Abstract}

Natural hydrogels have replaced synthetic hydrogels due to their properties such as long life, high water absorption capacity, high strength and resistance. Recently, hydrogels have been defined as two- or multicomponent systems consisting of three-dimensional networks of polymer chains that fill the space between macromolecules, and the efficiency of their water absorption depends on the polymeric nature and density of the polymer network connections. Due to climate change and frequent droughts, supply of fresh water has become one of the major barriers of sustainable aquaculture development in Iran. Therefore, wastewater treatment and reuse can be a suitable solution to meet the water requirement of expanding aquaculture industry. The purpose of the present study is to assess the efficiency of a new hydrogel prepared from agricultural waste (bagasse) in removal of nitrogen and phosphate compounds from the effluent of fish farms. First, the hydrogel was prepared during the polymerization process and then, in order to determine the optimal adsorption, it was tested in a discontinuous system by performing adsorption isotherm calculations. In cellulose/chitosan nanocrystalline hydrogel nanosorbent, the removal rates for nitrate, nitrite and phosphate were $84.3,86$ and $90.9 \%$, respectively. Optimal adsorption were determined at acidity 6 , time 30 minutes, temperature $40^{\circ} \mathrm{C}$, concentration $100 \mathrm{mg} / \mathrm{I}$ and adsorbent weight $0.5 \mathrm{~g}$. Comparison of adsorption isotherm models showed more conformity with Freundlich and Tamkin absorption models with correlation coefficients of 0.99 and 0.97 for nitrate, 0.98 and 0.91 for nitrite and 0.99 and 0.93 for phosphate, respectively.

\section{Highlights}

- New methods in the manufacture and preparation of nanosorbents were used

- Nanosorbents in wastewater treatment bioreactors and their wash ability without deformation were used

- It showed lower adsorbent and shorter duration compared to other adsorbents produced

- Simple use of herbal nanosorbents for fish farms was confirmed

- High ability of nanosorbents produced in the removal of nitrogen and phosphate compounds

\section{Introduction}

Extensive development of aquaculture increases the discharge of farm effluents into natural ecosystems such as surface waters and rivers, which contain large amounts of nitrogen and phosphate compounds, and its discharge into the aquatic environment causes degradation and adverse effects (Nora'aini et al., 2005). In aquatic ecosystems, the most common ionic forms of mineral nitrogen are ammonium (NH4), nitrate (NO3) and nitrite (NO2). These ions may enter aqueous media due to the entry of surface and groundwater runoff that is rich in nitrogen compounds (Skirrow, 1975; Gleick, 1993; Wetzel, 2001; Rabalais, 2002). Nitrate concentration in freshwater and marine ecosystems is higher than ammonium and nitrite (Rabalais, 2002). Nitrogenous compounds cause a nutrient-rich phenomenon in aquatic ecosystems that disrupts the balance of these ecosystems (Fernández-Nava et al., 2008). Biofloc and aquaponic systems have also been used in aquatic effluent treatment methods, but these systems have disadvantages such as increased energy for aeration and mixing, need for start-up period and alkaline supplementation, increase in pollution due to nitrate accumulation, and inconsistent and seasonal fluctuations.. 
Nowadays nanotechnology is used in various fields such as medicine, agriculture, fisheries and many other industries. In the fisheries industry, nanotechnology is used in various areas, which include fish growth improvement with the help of nanomaterials such as vitamins C, E and selenium in the aquatic diet, which causes weight gain and increases the level of antioxidants in blood (Zhou et al., 2009b). Also used in the preparation and production of vaccines to prevent bacterial and viral diseases in aquatic animals (Eldridge et al., 1990; Florence et al., 1995; Rajeshkumar et al., 2009) in polyimide hooks that attract fish due to light absorption (Rather et al., 2011 (Raissy and Ansari, 2011). One of the important features of adsorbents is adsorption capacity, adsorbent selectivity based on surface properties, reusability, compatibility with adsorbed material, and cost of its production and consumption (Saeedi et al., 2008). Criteria for selection of a good adsorbent include, good stability in time, wide range of temperature and acidity, high adsorption capacity, efficiency in removing contaminants, easy reabsorption of contaminants from the adsorbent, environmental characteristics such as degradability, environment friendly and low production costs. Cellulose is the most abundant natural polymer on earth, which is structurally a linear polymer composed of a glucose bond with 1, 4 beta glycoside bonds (Fig. 16) (Sticklen, 2008). Cellulose has many properties that are different and superior to polymers extracted from petroleum materials, such as degradability, biocompatibility, thermal stability, chemical stability and low production cost (Habibi et al., 2010; Tsioptsias et al., 2008). Nano celluloses have a crystalline and amorphous structure. Nanocellulose units are somewhat completely crystalline and have impressive and adjustable mechanical and chemical properties that have led to their use in a wide range of hydrophobic and hydrophilic composites such as hydrogels (De France et al., 2017). Cellulose nanofibers are able to interact between nanoparticle structures and form a polymer network by creating and establishing hydrogen bonds (Liang et al., 2007; Azeredo et al., 2010; Spagnol et al., 2012). Researchers have defined hydrogels in various ways, the most common of which is that a hydrogel is a water-swollen polymer network composed of several monomers, and another definition is a polymer that has the ability to swell and hold significant volume of water without dissolving (Buchholz and Graham, 1998; Li et al., 2013).

The ability of hydrogels to absorb water is due to the action of hydrophobic groups attached to the structure of the hydrogel, while their resistance to dissolution is due to the interconnection between the chains of the polymer network. Natural hydrogels have replaced synthetic hydrogels due to their properties such as long life, high water absorption capacity, high strength and resistance. Chitosan is a linear polysaccharide derived from chitin, the world's second most natural polymer (Shahidi et al., 1999). Chitosans with polycationic properties can be chemically and electrostatically bonded with negatively charged functional groups. Chitosan has properties such as biodegradability, environmentally friendly, availability, and absorption of cationic ions (Parhizgar et al., 2017). Chitosan is an abundant and available polysaccharide, which is renewable and degradable (Vold et al., 2003; Wu et al., 2010). Substitution of the catalyzed base on the steel group allows the formation of chitosan from chitin. It also increases the electron density and increases the affinity of the amine groups in chitosan and the positive ions in water. It also shows that the absorption capacity of chitosan at pH is close to neutral (Fig. 1-8) (Chassary et al., 2004).

In 2019, Manhooei et al. used cellulose nanocrystals modified with 3-chloropropyl trimethoxy silane to remove nitrate from aqueous solution. The results of this study showed that this adsorbent has a removal efficiency of $86.5 \%$ for nitrate. The study was performed under optimal acidity conditions of 7 , temperature $25^{\circ} \mathrm{C}$, concentration of $20 \mathrm{mg} / \mathrm{l}$, contact time of 10 minutes and adsorbent weight of $3 \mathrm{~g} / \mathrm{l}$. Nitrate uptake decreased in the presence of disturbing (interfering ??) ions such as sulfate, bicarbonate, chloride and phosphate. The results 
of the absorption isotherm in this study showed more conformity with the Freundlich and quasi-second-order synthetic model and an exothermic reaction. In 2017, Azadbakht et al. investigated the effect of plant adsorbent on cellulose nanocrystals extracted from bagasse in reducing nitrate from aqueous solution. Their result showed optimum absorbent at $\mathrm{pH}=6$, time $100 \mathrm{~min}$ and concentration $80 \mathrm{mg}$ and adsorbent weight $3 \mathrm{~g} / \mathrm{l}$ for natural adsorbent, and $\mathrm{pH}=6$, time $100 \mathrm{~min}$, concentration $80 \mathrm{mg}$ and $5.2 \mathrm{~g} / \mathrm{l}$ of adsorbent weight for surfactant activated adsorbent, respectively. The results of this study also showed that the rate of nitrate removal by natural adsorbent is $23.81 \%$ and by activated adsorbent $25 \%$. This study concluded that the performance of natural adsorbent with lower cost and better efficiency is more cost effective. In a study conducted by Sharma et al. (2018) on the extraction of nanocellulose from beach sheath grass to remove cadmium from water, the results indicated that more than $84 \%$ of cadmium is removed from water by nanocellulose and that it was most consistent with the Langmuir model. This study showed that nanocellulose can be used effectively in adsorption of heavy metals from water. The purpose of current study is to introduce a new and efficient adsorbent that can replace synthetic and chemical hydrogels and due to its biological and optimal performance can be introduced in the fields of water and wastewater treatment.

\section{Materials And Methods}

\section{Chemical compounds}

Sodium hydroxide $(\mathrm{NaOH})$, sulfuric acid (H2SO4), glacial acetic acid (CH3COOH), acrylic acid (C3H4O2), N, N'methylene base acrylic amide (C7H10N2O2) were supplied from Merck, Germany. Hydrochloric acid (HCl) was purchased from Sigma-Aldrich USA. Chitosan with a molecular weight of 50,000-80,000 daltons and a degree of distillation of $85-85 \%$ was purchased from Nano Novin Polymer Company.

\section{CNC production}

First, a $2 \% \mathrm{w} / \mathrm{w}$ solution of sodium hydroxide was used for 12 hours at room temperature under a magnetic stirrer to remove impurities. In order to complete the process of removing impurities, the obtained suspension was washed several times with distilled water, then during the process of acid hydrolysis using $64 \%$ sulfuric acid at $45^{\circ} \mathrm{C}$, it was continuously stirred for 1 hour. The resulting suspension was washed with distilled water and centrifuged at 10,000 rpm for 15 minutes. Centrifugation was continued until the supernatant reached $\mathrm{pH} 4$. Dialysis membranes were used to remove sulfate ions and reach a neutral $\mathrm{pH}$. After reaching neutral $\mathrm{pH}$, the suspension was stirred with a homogenizer at $450 \mathrm{rpm}$ for 1 hour.

\section{production Cellulose Nanocrystalline/ Chitosan hydrogel}

In order to make a hydrogel, first a suitable amount of chitosan in $30 \mathrm{ml}$ of acetic acid solution (1\% by volume) was poured into a three-hole balloon and placed on a magnetic stirrer and nitrogen gas was injected into it for 30 minutes to bubble out (??) oxygen from the container. Then the temperature was increased to $70^{\circ} \mathrm{C}$ and then $0.1 \mathrm{~g}$ of potassium persulfate was added to produce free radicals on the chitosan functional groups. After 10 minutes $3.60 \mathrm{~g}$ of acrylic acid and a portion of -NN methylene bisacrylamide was added to the solution for crosslinking, then $40 \mathrm{~g}$ of cellulose nanocrystalline gel was added. The temperature was maintained at $70^{\circ} \mathrm{C}$ for 2 hours, then the resulting hydrogel was cooled to room temperature with a $1 \mathrm{M}$ gain to reach $\mathrm{pH} 7$ after cooling. Finally, the hydrogel was washed with distilled water several times and dried in an oven at $70{ }^{\circ} \mathrm{C}$. Then it was ground using a mill and passed through a sieve. 


\section{Experimental design}

In order to determine the optimal absorption conditions, experiments were performed in a discontinuous order with three replications for each parameter, in such a way that during each experiment one of the parameters was variable and the other parameters were kept constant. Parameters studied during each experiment were, the effect of adsorbent weight $(0.1,0.2,0.5,0.8$ and $1 \mathrm{~g}), \mathrm{pH}(4,5,6,7$ and 8), concentration $(25,50,75$ and 100 $\mathrm{mg} / \mathrm{l})$, time $\left(10,15,30,60\right.$ and 90 minutes) and temperature $\left(25,30,40\right.$ and $\left.50{ }^{\circ} \mathrm{C}\right)$. The equations presented in table 1 were used to calculate the removal percentage and adsorption capacity.

The amount of adsorbed nitrogen and phosphate ions were calculated according to Equation (1) at time $t$, qt $(\mathrm{mg} / \mathrm{g})$ and at equilibrium qe $(\mathrm{mg} / \mathrm{g})$. In this regard, $\mathrm{CO}$ and $\mathrm{Ce}$ are the initial concentration and equilibrium concentration $(\mathrm{mg} / \mathrm{l})$, respectively. $\mathrm{Ct}(\mathrm{mg} / \mathrm{l})$ is the concentration of adsorbent per unit time and $\mathrm{Y}$ is the ratio of nitrogen and phosphate ion removal. qe is adsorption capacity $(\mathrm{mg} / \mathrm{g}), \mathrm{V}$ is solution volume $(\mathrm{L})$ and $\mathrm{m}$ adsorbent weight (g). Equation (2) was used to evaluate the adsorption capacity of nano absorbents. One of the isothermal models of adsorption is the Langmuir adsorption model, which is based on the assumption that adsorption takes place in a single layer at specific locations so that all absorption sites have the same energy and between surface molecules absorbent reactions do not take place (Equation (3)). In equation 3 , Ce is the equilibrium concentration $(\mathrm{mg} / \mathrm{l})$ and qmax is the adsorption capacity of the adsorbent monolayer in terms of $(\mathrm{mg} / \mathrm{g}-1)$ and $b$ is the absorption constant of Langmuir in terms of $(1 / \mathrm{mg}-1)$. In Freundlich absorption model, it is assumed that adsorption is multilayer, heterogeneous and non-uniform surface energy distribution. In this absorption model, equation (4) is described as reversible and multilayer. In this equation, the coefficients $\mathrm{Kf}$ and $\mathrm{n}$ are the absorption coefficients of the Freundlich isotherm, where $\mathrm{Kf}$ and $\mathrm{n}$ represent the adsorption capacity of the multilayer and the adsorption intensity, respectively. Ce is the equilibrium concentration in terms of $(\mathrm{mg} / \mathrm{I})$ and qe is the adsorption capacity in terms of ( $\mathrm{mg} / \mathrm{g}$ ). In the Tamkin model, it is assumed that the adsorption heat of all molecules in the adsorption layer decreases linearly due to the heterogeneous distribution of adsorption sites and the adsorption-adsorption interaction. Equation (5); in this equation, BT is related to the absorption heat, and bT is obtained only by solving the obedience equation, and KT is the equilibrium constant of the obedience isotherm. Ce is the equilibrium concentration in terms of $(\mathrm{mg} / \mathrm{I})$. In the quasi-first-order synthetic model (Lagergren model (Lagergren, 1898)), it is based on the assumption that adsorption takes place in the boundary layer and in which the changes are proportional to the number of unoccupied sites at the adsorbent surface (Ofomaja, 2010). Equation (6); in this equation, qe is the adsorption capacity in terms of $(\mathrm{mg} / \mathrm{g}$ ) the amount of nitrogen ions and phosphate adsorbed in terms of the amount of adsorbent unit at equilibrium, qt is the amount of ions adsorbed in terms of $(\mathrm{mg} / \mathrm{g}-1)$ at time $\mathrm{t}(\mathrm{min})$, and $\mathrm{k} 1$ is the speed constant. This equation was investigated by drawing a linear diagram In (qe-qt) versus $\mathrm{t}$. In the Ho quasi-second-order synthetic model (Ho and McKay, 2000) it is assumed that the chemical adsorption controlling the adsorption phenomenon and the rate of adsorption sites is proportional to the square of the number of unoccupied sites (Langeroodi, 2017 Equation (7).

In this equation, qe is the adsorbent capacity in terms of $(\mathrm{mg} / \mathrm{g})$ at equilibrium, qt is the amount of ions adsorbed at equilibrium $(\mathrm{mg} / \mathrm{g})$ and $\mathrm{K} 2$ is the second-order constant $(\mathrm{g} / \mathrm{mg}-1$. Min-1), with the graph of $\mathrm{t} / \mathrm{qt}$ versus $\mathrm{t}$ was determined. To calculate the thermodynamic parameters, the Van Hoff relation and the Gibbs free energy was used. In this Gibbs free energy equation, there are changes in the Gibbs free energy standard ( $\mathrm{kJ} / \mathrm{mol}$ ), enthalpy $(\mathrm{kJ} / \mathrm{mol})$ and entropy $(\mathrm{kJ} / \mathrm{mol})$. The negative Gibbs free energy indicates the spontaneity of the reaction and the positive enthalpy indicates that the solid-solution ratio is exothermic and the entropy increases randomly 
during the adsorption process (8.314 joules per mole). By drawing In qe/Ce on 1/T, enthalpy and entropy were calculated as equations (8) and (9).

\section{Characterization of Cellulose Nanocrystalline/ Chitosan hydrogel}

In order to study the morphological and internal structure of nanosorbents as well as the type of porosity, FESEM was used at Razi Metallurgical Laboratory and Bim Gostar Taban Laboratory (Tehran). To perform this test, the samples were first covered with a thin gold coating and studied using FESEM microscope model MIRA III and device MIRA3TESCAN-XMU model(made in Czech Republic) with different magnifications of 50-150 KX. TGA test was performed in the temperature range of $0-600{ }^{\circ} \mathrm{C}$ at a rate of $10{ }^{\circ} \mathrm{C} /$ minute using device TG $209 \mathrm{~F} 3$ $\mathrm{NETZSCH}$ (made in Germany). This test is to examine and discover how a substance behaves in various temperatures. XRD test was performed by the Dutch model PW1730 XRD to detect the crystal structure of the adsorbents in the angle range of $\theta-5.5^{\circ}$ and $\theta 2-70$ and temperature of $25^{\circ} \mathrm{C}$. This test is based on $\mathrm{X}$-ray diffraction and Bragg's law. EDS test was used to identify the constituent elements and determine their percentage in adsorbent. This test was performed using FESEM device manufactured by TESCAN(model MIRA III, Czech Republic). The FTIR test was performed to determine the functional groups in the structure of gravity with an infrared spectrometer in the wavelength range $(400-4000 / \mathrm{cm})$ with the FTIR Tensor II model by German company BruKer.

\section{Results}

In the experiment of the effect of adsorbent weight on the removal of nitrate, nitrite, phosphate parameters by hydrogel adsorbent synthesized under 60 minutes, acidity 5 , volumetric concentration of $100 \mathrm{mg} / \mathrm{l}$ of effluent and ambient temperature, the results showed that in the range of $0.1-1 \mathrm{~g}$, weight concentration of 0.1 to $0.5 \mathrm{~g}$, removal rate showed an increase of $67.69,73.91,70.9 \%$ for nitrate, nitrite and phosphate ions to $75.38,78.26$, and $86.36 \%$, respectively. In this experiment no significant increase was observed from the absorbent dose of 0.5 $\mathrm{g}$ to $1 \mathrm{~g}(\mathrm{P}<0.05)$. The optimum weight for cellulose-chitosan nanocrystalline hydrogel adsorbent was $0.5 \mathrm{~g}$ (Fig. 2). In the study of the effect of $\mathrm{pH}$ on the removal of the desired parameters, the results showed that at $\mathrm{pH} 4$ to 6 , the removal of nitrate, nitrite and phosphate ions showed a significant increase ranging from $75.38 \%, 80 \%$ and $87.27 \%$, respectively, but with further increase in $\mathrm{pH}$ (6 to 8 ) removal efficiency decreased by $43.07,42.6$ and $26.36 \%$ and the results showed that the optimal $\mathrm{pH}$ for effective removal of nitrate, nitrite and phosphate ions was 6 (Fig. 2). The effect of concentration on the removal rate of the desired parameters showed that at $\mathrm{pH} 6$, time 60 minutes and adsorbent weight of $0.5 \mathrm{~g}$, at a concentration of $100 \mathrm{mg} / \mathrm{l}$ with increasing concentration of $25 \mathrm{mg} / \mathrm{l}$ removal rate significantly increased $(\mathrm{P}<0.05)$ from $69.86,65.51,81.48 \%$ to $75.38,80,87.27 \%$ for nitrate, nitrite and phosphate ions, respectively. Therefore, a concentration of $100 \mathrm{mg} / \mathrm{l}$ was reported as the optimal concentration (Fig. 2). Examining the effect of time on effective removal of desired compounds using cellulosechitosan nanocrystalline hydrogels, the results showed that in the time range of 15 to 90 minutes, with increasing contact time from 15 to 30 minutes, the rate of removal increased from $69.23,78.26,86.36 \%$ to $75.38,80,87.27 \%$ for nitrate, nitrite and phosphate ions in 30 minutes, respectively, but from 30 to 90 minutes, no significant increase was observed in the removal of nitrate, nitrite and phosphate ions $(P<0.05)$ and time of 30 minutes was selected as the optimal time for cellulose-chitosan nanocrystalline hydrogel (Fig. 2).

The effect of temperature on the removal of nitrate, nitrite and phosphate ions using synthesized hydrogels at a concentration of $100 \mathrm{mg} / \mathrm{l}$, time 30 minutes, $\mathrm{pH} 6$ showed increasing the temperature from 25 to $40^{\circ} \mathrm{C}$ could 
elevate the removal efficiency by $84.3 \%, 86 \%$ and $90.9 \%$ for nitrate, nitrite and phosphate ions, respectively and no significant increase was observed at $50^{\circ} \mathrm{C}(\mathrm{P}<0.05)$. Therefore, $40^{\circ} \mathrm{C}$ was chosen as the optimal temperature (Fig. 2). In the study of isothermal adsorption models of cellulose-chitosan nanocrystalline hydrogel, the results showed that nitrate ion is most consistent with Freundlich and Tamkin adsorption models with correlation coefficients of 0.99 and 0.97. In nitrite ion, the highest agreement was in Tamkin and Freundlish models with correlation coefficient of 0.98 and 0.91 , respectively, and for phosphate ion, the highest agreement was in Freundlish, Tamkin and Langmuir models calculated with correlation coefficient of 0.99, 0.93 and 0.91 , respectively. The highest values of qm were measured in nitrite, nitrate and phosphate ions with values of 250 , 142.85 and 27.77, respectively. In Freundlich constants, the highest levels of $\mathrm{Kf}$ and $\mathrm{n}$ in phosphate ion and nitrite ions were calculated with 285.57 and 198.87 for adsorption capacity and intensity. The highest amount of Kt was measured in the Tamkin adsorption model for phosphate and nitrite ions with the rates of 26.31 and 14.01, respectively. In the study of quasi-first-order and quasi-second-order synthetic models, it shows more compatibility of nitrate, nitrite and phosphate ions with the second-order synthetic model with a coefficient of 1 for nitrate, 0.99 for nitrite and 0.99 for phosphate. In the first-order synthetic model, the maximum value calculated was $3.17 \mathrm{mg} / \mathrm{g}$ for the phosphate ion, followed by the qe for nitrite at $3 \mathrm{mg} / \mathrm{g}$ and for nitrate at 3.09 $\mathrm{mg} / \mathrm{g}$. In the second-order synthetic model, the maximum amount of qe for nitrate was estimated to be 0.49 $\mathrm{mg} / \mathrm{g}$ and the amount of $\mathrm{K} 2$ for nitrite was 58.82 per minute. In the study of thermodynamic model of nitrate, nitrite and phosphate ions, the results show that with increasing temperature, the amount of Gibbs free energy increased for nitrate, nitrite and phosphate ions.

The TGA curve of cellulose-chitosan nanocrystalline hydrogel indicates three temperature zones, in the first of which the weight loss from $25-200^{\circ} \mathrm{C}$ is related to the initial weight loss, which is mainly due to evaporation of water from cellulose sample. The second zone is related to severe weight loss and weight loss of $75.95 \%$, which continues from a temperature of $200^{\circ} \mathrm{C}$ to $400^{\circ} \mathrm{C}$. In the second zone, weight loss due to de-polymerization of chitosan chains is based on the decomposition and separation of glycosidic bonds, water depletion and decomposition of glycosyl units, resulting in the formation of volatiles and the subsequent formation of coal. After the second zone from $400^{\circ} \mathrm{C}$ to the final test temperature of $600^{\circ} \mathrm{C}$, the last degradation is the result of oxidation and decomposition of coal and reduction of molecular weight. The highest weight loss at $300^{\circ} \mathrm{C}$ was related to the thermal fluctuations of the polymer structure and the rapid evaporation of the polymer parts (Fig. 3).

The results of EDS analysis show that in the cellulose-chitosan nanocrystalline hydrogel, the amount of carbon elements was $47.94 \%$ by weight, $54.32 \%$ atomic, nitrogen amino group $11.45 \%$ by weight and $11.13 \%$ atomic, oxygen $40.61 \%$ and $34.5 \%$ by atomic weight (Fig. 3). Scanning electron image is made of nanocrystalline structure of cellulose and hydrogel, which indicates the porous structure and the presence of very small pores on the surface of the hydrogel, produced to absorb water. The image of cellulose nanocrystals shows the presence of cellulose networks in the structure of cellulose nanocrystals. Also, the average diameter of cellulose nanocrystals is $25 \mathrm{~nm}$ (Fig. 3).

Water absorption in cellulose/chitosan nanocrystalline hydrogel was $375 \%$. X-ray diffraction analysis shows hydrogel peaks at an angle $2 \theta$ of 12.5 and 20.1 degrees, which is due to the natural crystal structure in chitosan. A wide peak at an angle of 20 degrees indicates the semi-amorphous nature of chitosan. Peak increase is followed by increase in cellulose content, which results in de-crystallization. Crystallization is defined as the orientation of the crystals of a semi-crystalline matrix in the natural direction of cellulose nanocrystals. The 
presence of a peak at an angle of 22.5 degrees in the hydrogel structure is characteristic of the presence of nanocellulose. The peaks observed at the angle $2 \theta$ are equal to $14,18,22.5$ and 34.5 due to the presence of crystalline structure in cellulose nanocrystals. The peak increase of 12.5 degrees is due to an increase in chitosan yield of the hydrogel (Fig. 3). The FTIR curves before and after adsorption are shown in Fig. 3.

Peaks 1001, 1056, and 1157 indicate the tensile strength of the C-O, O-H, and C-N bands (Khan et al., 2014). Peaks 1715 and 1533 belong to chitosan amide groups I and II in the hydrogel structure, respectively (Li et al., 2012). Also, the strong band 1715 is related to the $C=0$ tensile bond in the di-aldehyde groups of cellulose nanocrystals. Bond 799 is related to the formation of new bonds of aldehyde groups with hydroxyl cellulose groups. The results indicate the successful oxidation of hydroxyl groups on the molecular chain of nanocrystalline cellulose to aldehyde groups (Xu et al., 2019). Extensive peaks 3200-3450 are related to O-H and $\mathrm{N}-\mathrm{H}$ tensile bond. The presence of peak $3342-2926$ is related to the symmetric and asymmetric vibrations of C$\mathrm{H}$. Peak 1583 also indicates the reaction of ester end groups on nanocellulose surfaces with chitosan amine groups (Celebi and Kurt, 2015; de Mesquita et al., 2012). Changes after adsorption indicate the presence of amine and aldehyde groups in the adsorption process.

\section{Discussions}

\section{Experiment on the effect of adsorbent weight}

Decrease in removal efficiency by increase in the adsorbent weight can be due to the high specific surface area of nanoparticles that have high reactivity and with increasing adsorption weight nanoparticles stick together and become lumps which reduces the specific surface area. In study on effect of adsorbent weight on the removal of nitrate, nitrite, phosphate parameters by synthesized hydrogel adsorbent under 60 minutes, acidity 5 , volume concentration of $100 \mathrm{mg} / \mathrm{I}$ of effluent and ambient temperature, the results showed that in the range of 0.1 to 1 $\mathrm{g}$, from weight concentration of 0.1 to $0.5 \mathrm{~g}$, removal rate incresaed from $67.69,73.91,70.9 \%$ to $75.38,78.26$, $86.36 \%$ for nitrate, nitrite and phosphate respectively, also no significant increase was observed from the absorbent dose of $0.5 \mathrm{~g}$ to $1 \mathrm{~g}(\mathrm{P}<0.05) .0 .5 \mathrm{~g}$ was determined as the optimum weight for cellulose-chitosan nanocrystalline hydrogel adsorbent. One of the most important factor in choosing the weight of the adsorbent to eliminate the desired parameters is cost-effectiveness of the adsorbent.. With increase in the weight of the adsorbent, the percentage removal increased in nanogels due to the elevation of sites and adsorption sites. The adsorption capacity decreases as the adsorbent exceeds the optimum value due to the unsaturation of some active sites due to the blockage and overlap of the sites. The decrease in removal efficiency can be due to the decrease in phosphate concentration gradient due to the increase in adsorbent weight, which is followed by a decrease in the removal driving force. The decrease in particle size efficiency at the nanoscale due to the increase in surface to volume ratio has a significant effect on the adsorption processes and achieveingthe optimal value, reducing the cost and attaining the maximum adsorption (Norisepehr et al., 2013). One of the important parameters in adsorption processes is to determine the amount of adsorbent weight in terms of performance and economics. Choosing the right weight of adsorbent can reduce wastewater treatment costs.

\section{Experiment on $\mathrm{pH}$ effect}

At acidic $\mathrm{pH}$, the functional groups present on the adsorbent surface due to the presence of $\mathrm{H}+$ ions in the protonated solution, increases the positive ion charge at the adsorbent surface and some kind of electric charge 
of the adsorbent surface occurs. The surface affects the functional groups involved in adsorption and causes electrostatic bonding in the adsorption phenomenon, and this type of bond between the adsorbent and the adsorbed results in increase of the removal rate. In the study of the effect of $\mathrm{pH}$ on the removal of the target parameters in the acidity range of 4 to 8 , the results showed that at $\mathrm{pH} 4$ to 6 , the removal of nitrate, nitrite and phosphate ions showed a significant increase and the removal rates were $75.38,80$ and $87.27 \%$, but with increase in $\mathrm{pH}$ from 6 to 8 , the removal efficiency decreased to 43.07, 42.6 and $26.36 \%$, respectively and the optimal pH was 6 for effective removal of nitrate, nitrite and phosphate. In pH experiment, the rate of elimination of electrostatic reactions between the adsorbent and the establishment of chemical reactions between the soluble ions and the adsorbent were monitored. In acidic conditions, the removal rate increases due to the establishment of electrostatic attraction, but in alkaline conditions, due to the presence of electrostatic repulsion forces, the removal rate decreases and causes a weak interaction between the absorbent and absorbing forces. Nitrate removal rate at $\mathrm{pH} 6$ using cellulose nanocrystals extracted from bagasse was reported to be $25 \%$ (Azadbakht, 2017). In 2016, Yang et al. examined cellulose-chitosan nanocrystalline aerogels for removing dye. Negatively charged factors absorb cationic dye. The aerogel produced showed the ability to remove the dye in the constant $\mathrm{pH}$ range up to a capacity of $785 \mathrm{mg} / \mathrm{g}$ (Yang et al., 2016).

\section{Experiment on the effect of concentration}

With increasing concentration, the adsorption rate increased, which can be due to the increase of active sites against elevating number of adsorbed ions. The initial concentration of driving force is necessary to overcome the resistance of nitrate, nitrite and phosphate ions to the active sites on the adsorbent surface. The higher initial concentration could lead to the higher efficiency and adsorption capacity. In the study on the effect of concentration on the removal of the target parameters, in terms of acidity 6 , time 60 minutes, absorbent weight of $0.5 \mathrm{~g}$ with increasing concentration of $25 \mathrm{mg} / \mathrm{I}$ at a concentration of $100 \mathrm{mg} / \mathrm{l}$, removal rate of $69.86,65.51$ and $81.48 \%$ increased to $75.38,80,87.27 \%$ for nitrate, nitrite and phosphate ions respectively, and concentration of $100 \mathrm{mg} /$ I was determined as the optimal and concentrations of 1.1, 0.23 and $0.14 \mathrm{mg} /$ I were estimated for nitrate, nitrite and phosphate ions, respectively. In a study conducted by Salehi Naseh et al., in 2017 using acrylic acid-based hydrogels on wheat bran and montmorillonite to remove copper, they reported that the adsorption rate increased with elevating concentration due to the driving force of mass transfer. In another study conducted by Azadbakht et al. in 2017 on nitrate removal using nanocrystalline cellulose, the results of the study showed that increasing the nitrate concentration from 30 to $100 \mathrm{mg} / \mathrm{I}$ increases the removal rate. Increasing the effects of electrostatic force could elevate the absorbent capacity.

\section{Experiment on the effect of contact time}

With increase in contact time, the probability of the adsorbed ions colliding with the adsorbent increases (Nemati et al., 2014). The adsorption of nitrate, nitrite and phosphate ions in the early hours increases rapidly due to the large number of active sites, but with increasing contact time, the amount of adsorption decreases due to clogging of adsorption sites. It could also be due to the decrease in the concentration of nitrogen and phosphate ions that were initially absorbed by the adsorbent and the decrease in the active surfaces available due to the overlap of the surface and the adhesion of the nanoparticles to each other. In examining the effect of duration on effective removal of desired compounds using cellulose-chitosan nanocrystalline hydrogels, the results show that in the time range of 15 to 90 minutes, with increasing contact time from 15 to 30 minutes, the removal rate of nitrate, nitrite and phosphate within 30 minutes increased from $69.23,78.26,86.36 \%$ to $75.38,80,87.27 \%$, 
respectively, but in 30 to 90 minutes range, no significant increase was observed in the removal of nitrate, nitrite and phosphate ions and 30 minutes was considered as the optimal time for cellulose-chitosan nanocrystalline hydrogel.

In the study on the effect of temperature $\left(25\right.$ to $\left.50^{\circ} \mathrm{C}\right)$, the rate of removal showed an increase in the amount of adsorption from 25 to $40^{\circ} \mathrm{C}$. Temperature is an important parameter in the physical and chemical processes of absorption processes. The positive effect of temperature increase on the adsorbent of cellulose-chitosan nanocrystalline hydrogel describes the adsorption process as anotherm, which can be due to factors such as rapid movement of ions and molecules due to increased heat and increase in the probability of ions colliding with the site. Also, this increase in temperature causes swelling in the internal structure of the adsorbent and bulking of the pores and porosity in the adsorbent surface and increases the adsorption sites and reduces the viscosity of the solution and easier penetration of nitrogen and phosphate ions. It described adsorbent surfaces and increased adsorption efficiency and increased removal. The effect of temperature on the removal of nitrate, nitrite and phosphate ions using synthesized hydrogels at a concentration of $100 \mathrm{mg} / \mathrm{l}$, time $30 \mathrm{minutes}, \mathrm{pH}$, temperature range 25 to $50^{\circ} \mathrm{C}$, results showed that by increasing the temperature from 25 to $40^{\circ} \mathrm{C}$, the removal efficiency and removal rates increase by $84.3,95,86$ and $90.9 \%$ for nitrate, nitrite and phosphate ions, respectively, and with increase in temperature from 40 to $50^{\circ} \mathrm{C}$ there was no significant increase $(P<0.05)$. Therefore, the temperature of $40^{\circ} \mathrm{C}$ was determined as the optimal temperature.

In the study of isothermal adsorption models of cellulose-chitosan nanocrystalline hydrogel, the results showed that nitrate ion is most consistent with Freundlich and Tamkin adsorption models with correlation coefficients of 0.99 and 0.97 . In the Freundlich model, it is assumed that the adsorption is heterogeneous and non-uniform with non-uniform adsorption energy. In the Tamkin model, it is assumed that the adsorption heat of all molecules at the adsorption surfaces decreases linearly, indicating the adsorption-adsorption interaction. In nitrite ion, the highest match was with Tamkin and Freundlish models with correlation coefficient of 0.98 and 0.91 , respectively, and also for phosphate ion, the match was calculated in Freundlish, Tamkin and Langmuir models with correlation coefficient of 99. 0.93 and 0.91, respectively. The results of the experiments at ambient temperature showed better match with the Tamkin model than the Langmuir and Freundlich models for nitrite ions, which can be due to the heterogeneous distribution of absorption sites. The highest values of qm were measured in nitrite, nitrate and phosphate ions, respectively, with values of 250, 142.85 and 27.77, respectively. In Freundlich constants, the highest levels of $\mathrm{Kf}$ and $\mathrm{n}$ in phosphate ion and nitrite ion were calculated with 285.57 and 198.87 for adsorption capacity and intensity. $\mathrm{Kf}$ is an important constant used to measure the relative absorption efficiency (synthetic). In the Freundlich model, the larger $n$ constant, the more desirable and indicates the optimal absorption. The Freundlich absorption model describes the reversibility of adsorption. The highest amount of Kt was measured in the obedience absorption model for phosphate and nitrite ions with the rates of 26.31 and 14.01, respectively. Adsorption models can determine the affinity of the adsorbent and the surface properties of the nanosorbent. The Freundlich model expresses the non-uniformity of the adsorbent surface and the Langmuir model expresses the uniformity of the adsorbent surface in order to absorb the desired parameters.

In 2018, Hokkanen et al. used a hydroxyapatite composite of bentonite clay and nanocellulose to remove phosphate, nickel and cadmium from aqueous solution. The results showed that the maximum adsorption for nickel, cadmium and phosphate were 29.46, 10.34 and $4.90 \mathrm{mlMol} / \mathrm{g}$, respectively. The reabsorption process was performed for metal ions with $0.1 \mathrm{M}$ nitric acid and for phosphate ions with $0.1 \mathrm{M}$ gain up to 5 re-adsorption cycles, the results of which showed that the removal rate was from 97-74\% for cadmium ion, it reduced by $98-$

Page $10 / 22$ 
$80 \%$ for nickel ions and $75-68 \%$ for phosphate ions (Hokkanen et al., 2018). The rate of phosphate removal using cellulose-chitosan nanocrystalline hydrogel produced was $90.9 \%$, which indicates the high adsorption capacity of the synthesized hydrogel in removing the phosphate composition. In a study conducted by Sharma et al. 2018 on the extraction of nanocellulose from beach sheath grass to remove cadmium from water, the results of this study indicate that more than $84 \%$ of cadmium is removed from water by nanocellulose and showed a high match with Langmuir model. This study showed that nanocellulose can be used effectively in adsorption of heavy metals from water (Sharma et al., 2018).

Synthetic models are highly dependent on the physical and chemical properties and structure and constituents of nanosorbents. In the study of quasi-first-order and quasi-second-order synthetic models, it is more consistent with nitrate, nitrite and phosphate ions with the second-order synthetic model with a coefficient of 1 for nitrate, 0.99 for nitrite and 0.99 for phosphate. In the study of the amount of qe in the first-order synthetic model, the maximum value was calculated for phosphate ions with a rate of $3.17 \mathrm{mg} / \mathrm{g}$, and then the amount of qe for nitrite and nitrate were 3 and $3.09 \mathrm{mg} / \mathrm{g}$. In the second-order synthetic model, the highest amount of qe for nitrate was $0.49 \mathrm{mg} / \mathrm{g}$ and the amount of $\mathrm{K} 2$ for nitrite was 58.82 per minute. $\mathrm{K} 2$ is a constant indicator of the rate of adsorption and indicates how fast the adsorption is done over time. In surface adsorption systems, in order to design the system and know the type of isotherms, the study of adsorption rate in the time interval has been determined, which determines the parameter of efficiency, removal and adsorption capacity (Jesus et al., 2011). Manhooei et al. reported the effect of 3-chloropropyl trimethoxy silane-modified cellulose nanocrystals had the highest nitrate adsorption agreement with the Freundlich and quasi-second-order synthetic model (Manhooei et al., 2019).

Positive entropy indicates an increase in irregularity in the adsorption process and an increase in the probability of collision of contaminant molecules with active sites at the nanosorbent surface. Also, positive entropy indicates the existence of some structural changes in the soluble and solid phases (Baharloui et al., 2017). In the study of thermodynamic model of nitrate, nitrite and phosphate ions, the results showed with increasing temperature, the amount of Gibbs free energy increased for nitrate, nitrite and phosphate, which indicates the high adsorption capacity at low temperature. Negative enthalpy indicates that the adsorption reaction is exothermic and the adsorption process is physical, and negative entropy indicates a reduction in irregularity and the placement of adsorbed ions on the adsorbent surface on a regular basis. The reaction between cellulose nanocrystals and chitosan forms a matrix polymer network, and aldehyde groups on the cellulose surface bond with free amine groups in chitosan (Fig. 2-5). Binders in polymer hydrogels are important in creating threedimensional networks and increasing water absorption. Hydrogels are hydrophilic polymer networks that do not dissolve in water due to crosslinking. Hydrogels with high functional groups of $\mathrm{OH}, \mathrm{NH} 2, \mathrm{COOH}, \mathrm{SO} H \mathrm{H}$ and COONa are able to absorb water at high rate (Zohuriaan-Mehr and Kabiri, 2008).

Cellulose hydrogels have received a lot of attention due to their intelligent behavior due to their cellulosic derivatives and non-toxicity. The use of binders in large quantities reduces the rate of swelling and water absorption, which is due to the reduction of the elastic behavior of the hydrogel network. The hydrogel produced in this study has covalent bonds due to the presence of a networking agent in the structure of the hydrogel, which increases the strength of the hydrogel. Covalent bonds between polymer chains are formed by the reaction of functional groups with the reactivity of amine-carboxylic acid groups (Akhtar et al., 2016). Chitosans are crosslinked under more favorable conditions by having amino groups. The strength part of the hydrogel is a network of bonded polymer chains. A three-dimensional grid, commonly known as a mesh. As shown in Figure 
$(3-5)$, each mesh is filled with spaces of a liquid that is normally water. The meshes hold the fluid and provide an elastic force that can be completed by expansion and contraction, and are therefore responsible for the hydrogel's strength. The ionic phase of hydrogels usually consists of ionization groups attached to polymer chains and a number of mobile ions due to the presence of the electrolyte solvent that surrounds the hydrogel (Ullah et al., 2015).

In a system of discontinuous reactors, nanosorbents enter the system from the very beginning and are mixed vigorously by rotary agitators for a specified and optimal time, and after elapse of a specified time and the reaction processes, the contents of the reactor are removed. No material or compound enters or leaves the system during reactor operation. Temperature control in the system is very important due to the exothermic and endothermic absorption reactions. As a result, the contents of the system may continuously increase or decrease due to ambient temperature during the operation of the reactors, disrupting the adsorption reactions and reducing the adsorption capacity and efficiency. Heat exchangers can be used to regulate the temperature during the adsorption reaction, which can be done by pipes that control the temperature inside the system by passing hot and cold currents. The operation and the speed of the agitator inside the system are of great importance because if the mixing is not done well, there is no possibility of reaction and collision between the adsorbent and the adsorbent. The shape design of stirrers depends on various factors such as the shape and volume of the tanks and the speed and intensity of the flow inside the system. The use of polymer reactors can keep the temperature constant throughout the system during the absorption reaction (Fig. 5).

\section{Conclusions}

Adherence to the principles of green chemistry is essential in biological and environmental studies, especially in aquatic ecosystems. The principles of green chemistry state that product design is done with minimal risk. The results of this study showed the use of plant nanocrystalline cellulose/chitosan with optimal adsorption conditions can have a good performance in removing nitrate, nitrite and phosphate compounds from the effluent of fish farms. The introduced nano-adsorbent can be used as a new adsorbent that has properties such as environmental friendliness and biodegradability. The synthesized cellulose-chitosan nanocrystallized hydrogel nanosorbent can have a removal efficiency of $84.3,86$ and $90.9 \%$ for nitrate, nitrite and phosphate ions, respectively. Cellulose/chitosan crystal plant nanohydrogels showed the highest removal rate for phosphate ions. Nano-adsorption without sludge production has the ability to remove the desired compounds and can be easily removed from the culture system and will not pose a risk to the environment. The nano-adsorbent is easily usable and can be used for small and large farms. Therefore, this study on the performance of adsorbent and its structures indicate the desired capability of this adsorbent.

\section{Declarations}

\section{Funding}

The authors declare that no funds, grants, or other support were received during the preparation of this manuscript.

\section{Competing Interests}

The authors have no relevant financial or non-financial interests to disclose. 
Author contribution: Fatemeh Darabitabar: Investigation, Methodology, Visualization; Vahid Yavari: Project administration, Supervision, Resources' Writing - review \& editing; Aliakbar Hedayati: Writing - original draft, Data curation, Validation; Mohammad Zakeri: Conceptualization; Hossein Yousefi: Formal analysis, Software.

Data availability: The data is available from the corresponding author on reasonable request.

Ethical approval and consent to participate: Not applicable

Consent for publication: Not applicable

Competing interests: The authors declare no competing interests

\section{References}

1. Akhtar MF, Hanif M, Ranjha NM (2016) Methods of synthesis of hydrogels... A review. Saudi Pharm J 24(5):554-559

2. Azadbakht P, Pourzamani H, Petroudy J, Bina R, B (2017) Removal of nitrate from aqueous solution using nanocrystalline cellulose. Int J Environ Health Eng 5(2):1-6

3. Azeredo HM, Mattoso LHC, Avena-Bustillos RJ, Filho GC, Munford ML, Wood D, McHugh TH (2010) Nanocellulose reinforced chitosan composite films as affected by nanofiller loading and plasticizer content. J Food Sci 75(1):N1-N7

4. Buchholz FL, Graham AT (1998) Modern superabsorbent polymer technology. John! Wiley \& Sons, Inc, 605 Third Ave, New York, NY 10016, USA, 1998. 279

5. Chassary P, Vincent T, Guibal E (2004) Metal anion sorption on chitosan and derivative materials: a strategy for polymer modification and optimum use. Reactive and Functional Polymers 60:137-149

6. De France KJ, Hoare T, Cranston ED (2017) Review of hydrogels and aerogels containing nanocellulose. Chem Mater 29(11):4609-4631

7. Eldridge JH, Hammond CJ, Meulbroek JA, Staas JK, Gilley RM, Tice TR (1990) Controlled vaccine release in the gut-associated lymphoid tissues. I. Orally administered biodegradable microspheres target the Peyer's patches. J Controlled Release 11(1-3):205-214

8. Fernández-Nava Y, Maranon E, Soons J, Castrillón L (2008) Denitrification of wastewater containing high nitrate and calcium concentrations. Bioresour Technol 99(17):7976-7981

9. Florence AT, Hillery AM, Hussain N, Jani PU (1995) Nanoparticles as carriers for oral peptide absorption: studies on particle uptake and fate. J Controlled Release 36(1-2):39-46

10. Gleick PH (1993) Water and conflict: Fresh water resources and international security. Int Secur 18(1):79112

11. Habibi Y, Lucia LA, Rojas OJ (2010) Cellulose nanocrystals: chemistry, self-assembly, and applications. Chem Rev 110(6):3479-3500

12. Ho Y-S, McKay G (2000) The kinetics of sorption of divalent metal ions onto sphagnum moss peat. Water Res 34(3):735-742

13. Hokkanen S, Bhatnagar A, Srivastava V, Suorsa V, Sillanpää M (2018) Removal of Cd2+, Ni2 + and PO43 from aqueous solution by hydroxyapatite-bentonite clay-nanocellulose composite. Int J Biol Macromol 
118:903-912

14. Jesus A, Romão L, Araújo B, Costa A, Marques J (2011) Use of humin as an alternative material for adsorption/desorption of reactive dyes. Desalination 274(1-3):13-21

15. Kabiri K, Omidian H, Zohuriaan-Mehr M, Doroudiani S (2011) Superabsorbent hydrogel composites and nanocomposites: a review. Polym Compos 32(2):277-289

16. Lagergren SK (1898) About the theory of so-called adsorption of soluble substances. Sven Vetenskapsakad Handingarl 24:1-39

17. Langeroodi NS (2017) Equilibrium and kinetics of biosorption of oxalic acid by wheat straw. Russian J Phys Chem B 11(2):318-323

18. Liang S, Zhang L, Li Y, Xu J (2007) Fabrication and properties of cellulose hydrated membrane with unique structure. Macromol Chem Phys 208(6):594-602

19. Manhooei L, Mehdinejadiani B, Amininasab SM (2019) Cellulose nanocrystal modified with 3-chloro propyl trimethoxysilane: a new bio-adsorbent for nitrate removal from water. Water and Environment Journal

20. Manhooei L, Mehdinejadiani B, Amininasab SM (2019) Cellulose nanocrystal modified with 3-chloro propyl trimethoxysilane: a new bio-adsorbent for nitrate removal from water. Water and Environment Journal

21. Nora'aini A, Mohammad AW, Jusoh A, Hasan M, Ghazali N, Kamaruzaman K (2005) Treatment of aquaculture wastewater using ultra-low pressure asymmetric polyethersulfone (PES) membrane. Desalination 185(1-3):317-326

22. Norisepehr M, Golbaz S, Jarghi S (2013) Comparision of Chitosan Function as Adsorbent for Nitrate Removal Using Synthetic Aqueous Solution and Drinking Water. J Environ Health Eng 1(1):11-19

23. Ofomaja AE (2010) Intraparticle diffusion process for lead (II) biosorption onto mansonia wood sawdust. Bioresour Technol 101(15):5868-5876

24. Parhizgar F, Alishahi A, Varasteh H, Rezaee H (2017) Removing sodium dodecyl benzene sulfonate (SDBS) from aqueous solutions using chitosan. J Polym Environ 25(3):836-843

25. Raissy M, Ansari M (2011) In vitro antimicrobial effect of silver nanoparticles on Lactococcus garvieae and Streptococcus iniae. Afr J Microbiol Res 5(25):4442-4445

26. Rajeshkumar S, Venkatesan C, Sarathi M, Sarathbabu V, Thomas J, Basha KA, Hameed AS (2009) Oral delivery of DNA construct using chitosan nanoparticles to protect the shrimp from white spot syndrome virus (WSSV). Fish Shellfish Immunol 26(3):429-437

27. Rather M, Sharma R, Aklakur M, Ahmad S, Kumar N, Khan M, Ramya V (2011) Nanotechnology: a novel tool for aquaculture and fisheries development. A prospective mini-review. Fisheries and Aquaculture Journal 16(1-5):3

28. Shahidi F, Arachchi JKV, Jeon Y-J (1999) Food applications of chitin and chitosans. Trends Food Sci Technol 10(2):37-51

29. Sharma PR, Chattopadhyay A, Sharma SK, Geng L, Amiralian N, Martin D, Hsiao BS (2018) Nanocellulose from spinifex as an effective adsorbent to remove cadmium (II) from water. ACS Sustain Chem Eng 6(3):3279-3290

30. Sharma PR, Chattopadhyay A, Sharma SK, Geng L, Amiralian N, Martin D, Hsiao BS (2018) Nanocellulose from spinifex as an effective adsorbent to remove cadmium (II) from water. ACS Sustain Chem Eng 6(3):3279-3290 
31. Skirrow G (1975) The dissolved gases: carbon dioxide. In: Riley JP, Skirrow G (eds) Chemical oceanography, vol 2, 2nd edn. Academic Press, London, London

32. Spagnol C, Rodrigues FH, Pereira AG, Fajardo AR, Rubira AF, Muniz EC (2012) Superabsorbent hydrogel composite made of cellulose nanofibrils and chitosan-graft-poly (acrylic acid). Carbohydr Polym 87(3):2038-2045

33. Sticklen MB (2008) Plant genetic engineering for biofuel production: towards affordable cellulosic ethanol. Nat Rev Genet 9(6):433-443

34. Tsioptsias C, Stefopoulos A, Kokkinomalis I, Papadopoulou L, Panayiotou C (2008) Development of microand nano-porous composite materials by processing cellulose with ionic liquids and supercritical CO 2. Green Chem 10(9):965-971

35. Ullah F, Othman MBH, Javed F, Ahmad Z, Akil HM (2015) Classification, processing and application of hydrogels: A review. Mater Sci Engineering: C 57:414-433

36. Vold IM, Vårum KM, Guibal E, Smidsrød O (2003) Binding of ions to chitosan-selectivity studies. Carbohydr Polym 54(4):471-477

37. Wetzel R (2001) Bacterioplankton. Limnology. Lake and river ecosystems, 3rd edn. Academic Press, New York, NY, pp 489-525

38. Wu F-C, Tseng R-L, Juang R-S (2010) A review and experimental verification of using chitosan and its derivatives as adsorbents for selected heavy metals. J Environ Manage 91(4):798-806

39. Yang H, Sheikhi A, van de Ven TG (2016) Reusable green aerogels from cross-linked hairy nanocrystalline cellulose and modified chitosan for dye removal. Langmuir 32(45):11771-11779

40. Zhou M, Wang W, Chi M (2009a) Enhancement on the simultaneous removal of nitrate and organic pollutants from groundwater by a three-dimensional bio-electrochemical reactor. Bioresour Technol 100(20):4662-4668

41. Zhou X, Wang Y, Gu Q, Li W (2009b) Effects of different dietary selenium sources (selenium nanoparticle and selenomethionine) on growth performance, muscle composition and glutathione peroxidase enzyme activity of crucian carp (Carassius auratus gibelio). Aquaculture 291(1-2):78-81

42. Zohuriaan-Mehr MJ, Kabiri K (2008) Superabsorbent polymer materials: a review. Iran Polym J 17(6):451

\section{Tables}

Table 1 is available in the Supplemental Files section. 
Table 1

Isotherm models and kinetic and coefficients

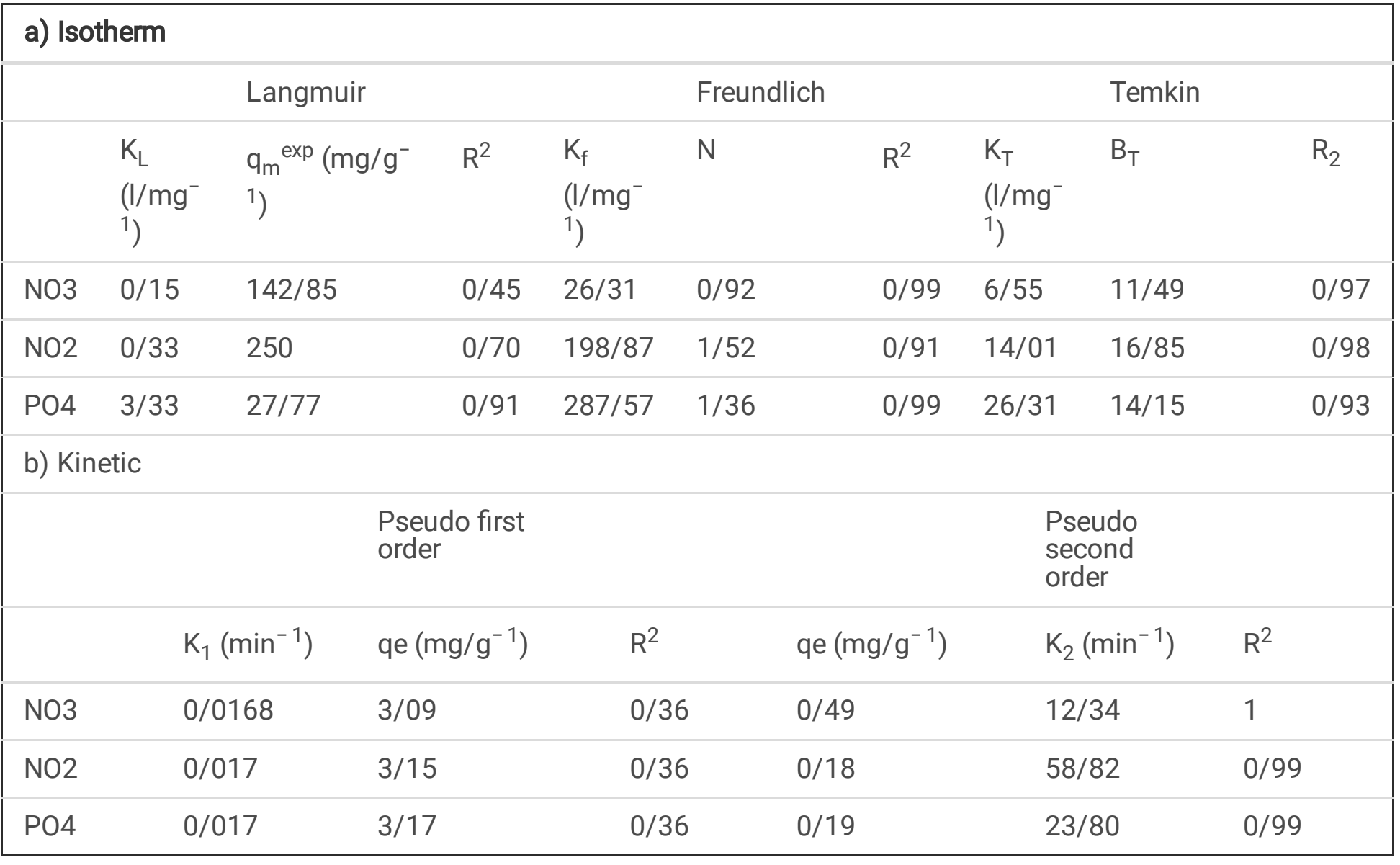


Table 2

Thermodynamic parameters at different temperatures

\begin{tabular}{|llll|}
\hline $\mathrm{T}(\mathrm{K})$ & $\Delta \mathrm{G}^{\circ}(\mathrm{kj} / \mathrm{mol})$ & $\Delta \mathrm{H}^{\circ}(\mathrm{kj} / \mathrm{mol})$ & $\Delta \mathrm{S}^{\circ}\left(\mathrm{kj} / \mathrm{mol}^{-\mathrm{K}^{-1}}\right)$ \\
\hline 298 & $47 / 20-$ & $53 / 11-$ & $0 / 03$ \\
303 & $62 / 20-$ & $*$ & $*$ \\
313 & $92 / 20-$ & $*$ & $*$ \\
323 & $22 / 21-$ & $*$ & $*$ \\
$\mathrm{~T}(\mathrm{~K})(\mathrm{NO})$ & $\Delta \mathrm{G}^{\circ}(\mathrm{kj} / \mathrm{mol})$ & $\Delta \mathrm{H}^{\circ}(\mathrm{kj} / \mathrm{mol})$ & $\Delta \mathrm{S}^{\circ}\left(\mathrm{kj} / \mathrm{mol}^{-\mathrm{K}^{-1}}\right)$ \\
\hline 298 & $14 / 8-$ & $16 / 5-$ & $01 / 0-$ \\
303 & $19 / 8-$ & $*$ & $*$ \\
313 & $29 / 8-$ & $*$ & $*$ \\
323 & $39 / 8-$ & $*$ & $*$ \\
$\mathrm{~T}(\mathrm{~K})(\mathrm{NO3})$ & $\Delta \mathrm{G}^{\circ}(\mathrm{kj} / \mathrm{mol})$ & $\Delta \mathrm{H}^{\circ}(\mathrm{kj} / \mathrm{mol})$ & $\Delta \mathrm{S}^{\circ}\left(\mathrm{kj} / \mathrm{mol}^{-1}\right)$ \\
\hline 298 & $54 / 16-$ & $6 / 7-$ & $0 / 03$ \\
303 & $69 / 16-$ & $*$ & $*$ \\
313 & $99 / 16-$ & $*$ & $*$ \\
\hline 323 & $29 / 17-$ & $*$ & $*$ \\
\hline
\end{tabular}

Figures 




Figure 1

Cellulose Nanocrystalline/ Chitosan hydrogel (a), Cellulose Nanocrystalline/ Chitosan hydrogel before water absorption (b), Cellulose Nanocrystalline/ Chitosan hydrogel after water absorption (c) 

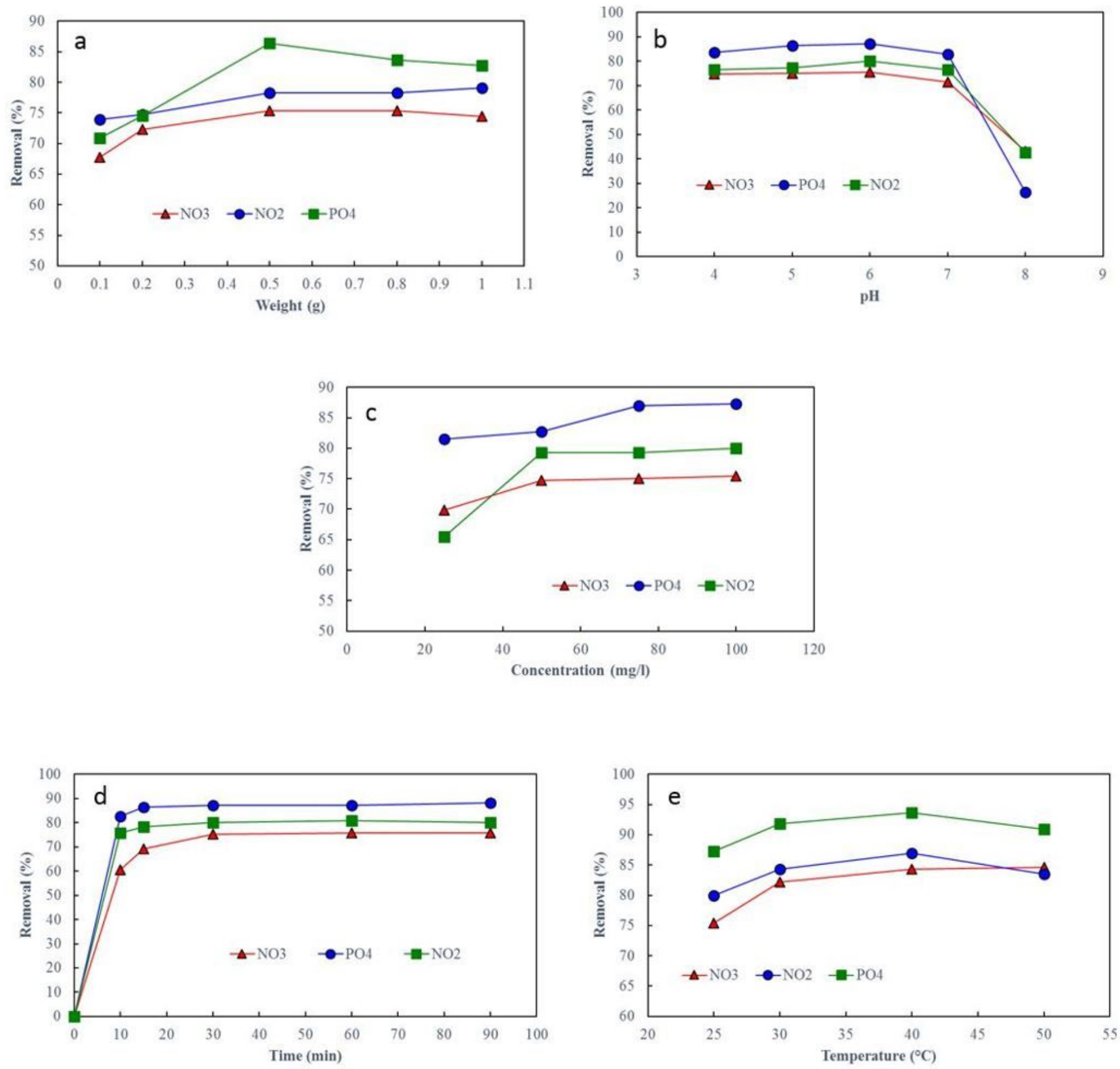

\section{Figure 2}

The effect of different adsorption parameters on the phosphate, nitrite and nitrate compounds by Cellulose Nanocrystalline/Chitosan hydrogel adsorbent a) Weight, b) pH, c) Concentration, d) Time, e) Temperature 



Figure 3

Characteristics of Cellulose Nanocrystalline/Chitosan hydrogel adsorbent. a) FESEM, b) FTIR before and after adsorption, c) TGA, d) XRD before and after adsorption and e) EDS 


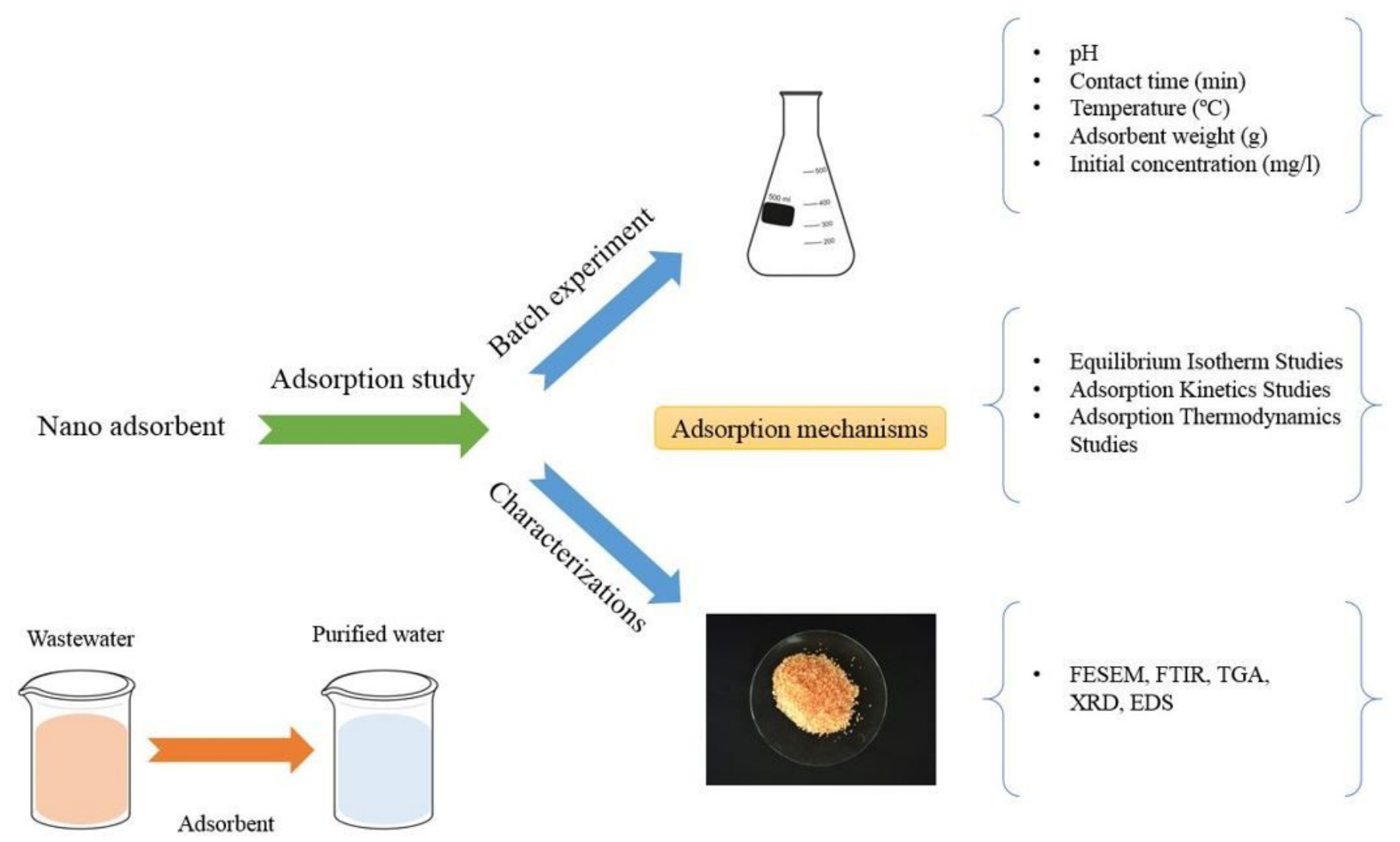

Figure 4

Adsorption studies based on discontinuous adsorption system 

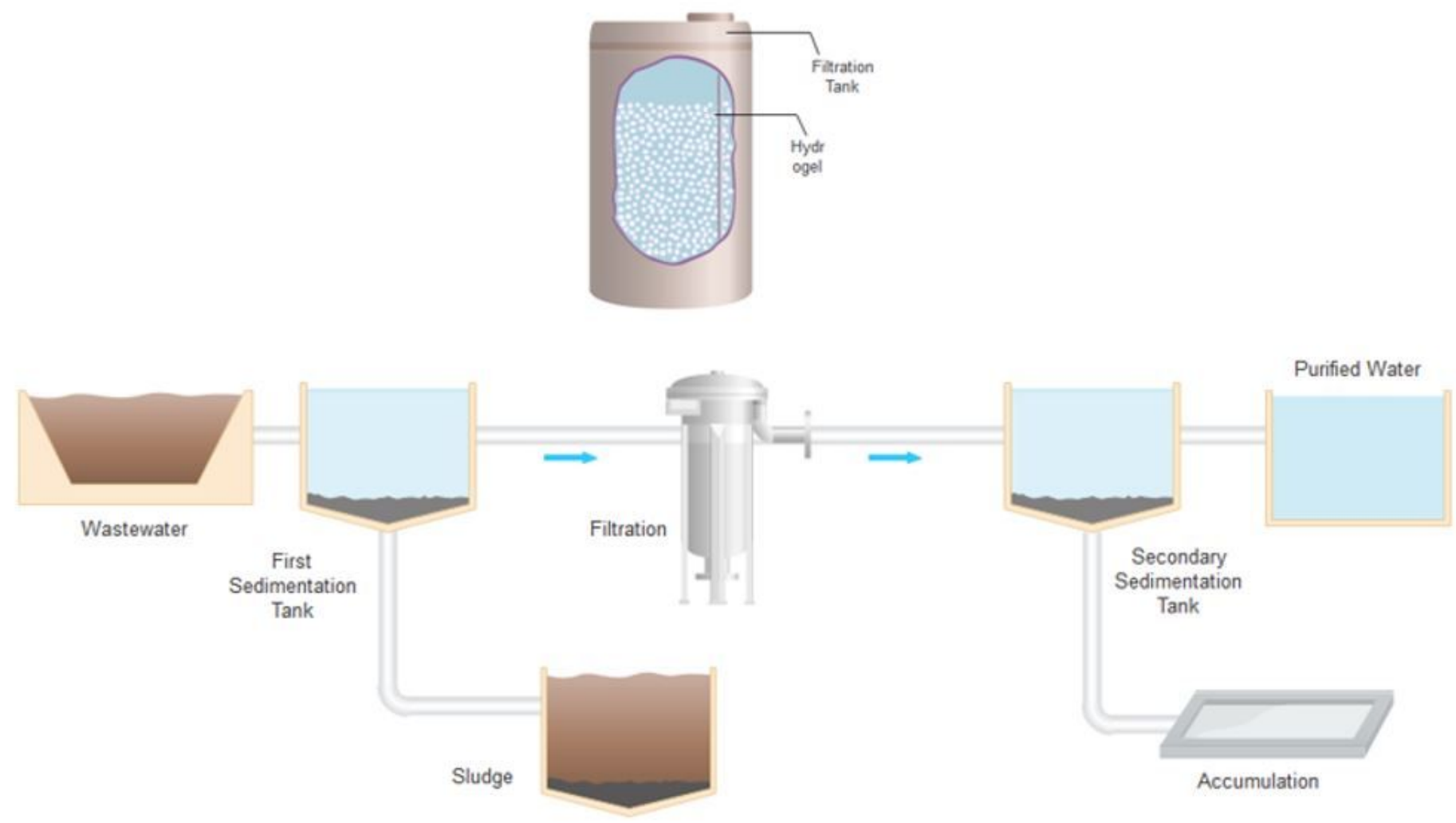

Figure 5

Modeling of effluent treatment system with nano adsorbent produced

\section{Supplementary Files}

This is a list of supplementary files associated with this preprint. Click to download.

- GA.jpg

- Table1.jpg 